\title{
Conotruncal heart defect/microphthalmia syndrome: delineation of an autosomal recessive syndrome
}

\author{
M C Digilio, B Marino, A Giannotti, B Dallapiccola
}

\begin{abstract}
We report on three sibs born to healthy parents, one livebirth and two terminated pregnancies, presenting with a malformation complex characterised by conotruncal heart defect (CTHD), microphthalmia, genital anomalies, and facial dysmorphism. The recurrence of the association of CTHD, particularly truncus arteriosus, and microphthalmia in sibs has previously been reported in rare instances, but a correlation between the single descriptions has never been noted. CTHDs are included among the cardiac malformations characteristically associated with the group of syndromes caused by the microdeletion of chromosome 22q11, but no detectable hemizygosity has been found in our family. An autosomal recessive gene seems to be involved in syndromic patients with the combination of CTHD and microphthalmia. The map location of this gene is at present unknown, but autosomal recessive inheritance must be considered in genetic counselling of families with children presenting with this malformation complex. $(F$ Med Genet 1997;34:927-929)
\end{abstract}

Keywords: congenital heart defect; truncus arteriosus; tetralogy of Fallot; microphthalmia

Departments of

Medical Genetics and

Paediatric Cardiology,

Bambino Gesù

Hospital, Piazza S

Onofrio 4, 00165 Rome,

Italy

M C Digilio

B Marino

A Giannotti

Department of Human Genetics, University of Tor Vergata, Rome, and CSS Hospital, San Giovanni Rotondo, Italy

B Dallapiccola

Correspondence to: Dr Digilio.

Received 22 November 1996 Revised version accepted for publication 21 April 1997
Autosomal dominant transmission of conotruncal heart defects (CTHDs) in the setting of syndromes resulting from 22q11 microdeletion, including DiGeorge, velocardiofacial, and conotruncal anomaly-face syndromes, has been previously well described. ${ }^{1-3}$ Nonsyndromic CTHDs seem to be inherited as a multifactorial trait, ${ }^{4}$ although monogenic autosomal recessive inheritance has been suspected in some instances. ${ }^{5-12}$

The recurrence of CTHD, particularly truncus arteriosus (TA), and ocular anomalies in sibs with malformation complexes has been reported, ${ }^{13-15}$ but a correlation between these single descriptions has never been noted.

We report here on three sibs, one livebirth and two terminated pregnancies, all presenting with a syndrome characterised by CTHD and microphthalmia, and suggest autosomal recessive inheritance of this genetic condition.

\section{Case reports}

CASE 1

The infant, a female, was born by caesarean section at 38 weeks of gestation. Ultrasound examination in the 18 th week of pregnancy indicated retarded fetal growth and cardiac malformation was diagnosed in the 20th week. Birth weight was $1510 \mathrm{~g}$, length $39 \mathrm{~cm}$, and OFC $22 \mathrm{~cm}$. Apgar scores were 3 at one minute and 5 at five minutes. Clinical evaluation showed bilateral microphthalmia, hypertelorism, a small mouth, narrow palate, dysmorphic ears, webbed neck, and bilateral rocker bottom feet.

Ophthalmological examination showed microphthalmos. The pupillary light reactions were normal, the anterior chambers were shallow, and the optic discs were pale. There was no evidence of coloboma of the iris, retina, choroid, or optic disc. Echocardiography showed tetralogy of Fallot and cerebral ultrasound examination indicated periventricular leucomalacia. Renal ultrasonography showed an ectopic right kidney and a normal left kidney. Chromosomal analysis on peripheral lymphocytes showed a normal female karyotype. Fluorescent in situ hybridisation with probe Sc11.1 ${ }^{16}$ failed to identify a 22q11 microdeletion. Slight thrombocytopenia, ranging from 70-85 $\times 10 / 1$, was detected in the first week of life. The baby died at 35 days because of severe hypoxia. Necropsy confirmed cerebral, ocular, cardiac, and renal anomalies. Bilateral streak ovaries were also found. Owing to the detection of thrombocytopenia, histological examination of spinal bone marrow was performed and showed normal quantitative representation of all cellular maturation stages.

FAMILY HISTORY

The proband was the third pregnancy of healthy, non-consanguineous parents. The mother was 24 years old at the time of birth and the father 27. Both were born in a small village and the paternal grandparents were first cousins. There were two previous pregnancies, which were voluntarily terminated because of multiple fetal malformations. The clinical features of the sibs are summarised in table 1 and information about the older sibs is given below.

CASE 2

The pregnancy was complicated by threatened abortion in the second month. Fetal ultrasonography at 18 and 21 weeks showed 
Table 1 Clinical findings in patients with the association of conotruncal heart defect and microphthalmia

\begin{tabular}{|c|c|c|c|c|c|c|c|c|c|c|c|}
\hline \multirow[b]{2}{*}{ Characteristics } & \multicolumn{3}{|c|}{ Gardner et $a l^{l 3}$} & \multicolumn{2}{|c|}{ Thomas et al ${ }^{14}$} & \multicolumn{3}{|c|}{ Figuera et al ${ }^{\text {s }}$} & \multicolumn{3}{|c|}{ Present cases } \\
\hline & 1 & 2 & 3 & 1 & 2 & 1 & 2 & 3 & 1 & 2 & 3 \\
\hline Sex & $\mathbf{F}$ & $\mathbf{M}$ & $\mathrm{F}$ & $\mathbf{M}$ & $\mathbf{M}$ & $\mathbf{M}$ & $\mathrm{F}$ & $\mathbf{F}$ & $\mathbf{F}$ & $\mathbf{M}$ & $\mathbf{M}$ \\
\hline Microphthalmia & + & + & + & + & + & + & + & + & + & + & + \\
\hline Craniofacial anomalies & + & + & + & + & + & + & + & + & + & + & + \\
\hline Congenital heart defect & VSD? & - & $\mathrm{TA}+\mathrm{MA}$ & TA & TA & TF & - & - & TF & TA & TA \\
\hline Renal anomaly & & - & + & + & - & & & & + & - & - \\
\hline Genital anomaly & - & + & - & - & - & - & - & - & + & + & - \\
\hline Camptodactyly & - & - & + & + & + & & + & + & - & & \\
\hline Club foot & - & - & + & - & - & - & - & - & + & - & - \\
\hline Thrombocytopenia & + & + & + & & & & & & + & & \\
\hline
\end{tabular}

$\mathrm{VSD}=$ ventricular septal defect, $\mathrm{TA}=$ truncus arteriosus, $\mathrm{MA}=$ mitral atresia, $\mathrm{TF}=$ tetralogy of Fallot.

retarded fetal growth and cardiac malformation consisting of a truncus arteriosus type II was diagnosed in the 18 th week. Chromosomal analysis on amniocytes showed a normal male karyotype $(46, \mathrm{XY})$. The pregnancy was terminated in another institution in the 25th week. Necropsy showed a microbrachycephalic skull, bilateral severe microphthalmia, epicanthic folds, flat nasal bridge, micrognathia, small and low set ears, short neck with loose skin, bilateral cryptorchidism, and malpositioned toes. Cardiac malformations consisted of truncus arteriosus type II, infundibular ventricular septal defect, and hypoplastic pulmonary arteries. No cerebral, lung, gastrointestinal, or renal abnormalities were detected.

\section{CASE 3}

This pregnancy was also terminated in another institution at 24 weeks of gestation after ultrasound detection of congenital malformations. Necropsy showed a male fetus with facial dysmorphism, including bilateral microphthalmia and microretrognathia. The lungs were hypoplastic and truncus arteriosus type II was also present. No additional anomalies were detected.

\section{Discussion}

To our knowledge, the combination of TA and microphthalmia has been previously reported in two sibships, independently described as affected by a new genetic condition. ${ }^{13}{ }^{14}$ Furthermore, microphthalmia associated with tetralogy of Fallot has been noted in an additional family. ${ }^{15}$ The major clinical findings of these patients are summarised in table 1 . We believe that CTHDs and microphthalmia, often associated with other congenital malformations, are the cardinal features of a genetic syndrome inherited as an autosomal recessive trait.

Microphthalmia is a congenital malformation affecting 1.2-1.8 in 10000 births. ${ }^{17}$ Three aetiological classes have been identified, including microphthalmia resulting from monogenic and chromosomal genetic disorders, prenatally acquired diseases, and associations such as CHARGE and VATER. ${ }^{17}$

TA is included among the cardiac malformations characteristically associated with DiGeorge syndrome. ${ }^{18}$ Chromosome 22q11 microdeletion is a frequent cause of CTHD in the setting of DiGeorge and velocardiofacial syndromes. ${ }^{19}$ In addition, around $20 \%$ of patients with TA have hemizygosity for 22q11. ${ }^{21}$ However, no. detectable 22q11 deletion has been found in our family. Interestingly, this chromosomal anomaly has never been detected in families with recurrence of non-syndromic CTHD in sibs. ${ }^{22}{ }^{23}$ The existence of an autosomal recessive gene presumably not located in the $22 \mathrm{q} 11$ region causing CTHDs is possible, and this is further corroborated by the report of parental consanguinity in some instances of recurrent TA. ${ }^{59}$ An autosomal recessive gene also seems to be involved in syndromic patients affected by the combination of TA and microphthalmia, although the map location of this presumed gene is at present unknown. The autosomal recessive inheritance must be taken into consideration in genetic counselling of families with isolated CTHD, but particularly in those with TA and associated extracardiac anomalies not resulting from 22q11 microdeletion. The types of CTHD observed in the present family confirm the pathogenetic similarities between TA and tetralogy of Fallot. ${ }^{24}$

The study of families with recurrent CTHDs must be continued, with particular regard to familial cases without del $(22 \mathrm{q} 11){ }^{22}{ }^{23}$ Different genes involved in the morphogenesis of CTHDs may be identified, as well as their connection with neural crest abnormalities, which is now the best known pathogenetic mechanism to be related to anomalies of the outflow tracts of the heart. ${ }^{25}$ Since genes different from those located in chromosomal region $22 \mathrm{q} 11$ can cause CTHDs, two alternative pathogenetic pathways can be hypothesised: (1) this new gene/genes could influence the neural crest following mechanisms similar to those suggested for deletion $22 \mathrm{q} 11$, and (2) this new gene/genes could cause the CTHDs by different and unknown pathogenetic mechanisms.

1 Scambler PJ, Carey AH, Wyse RKH, et al. Microdeletions within 22q11 associated with sporadic and familial DiGeorge syndrome. Genomics 1991;10:201-6.

2 Wilson DI, Goodship JA, Burn J, Cross JE, Scambler PJ. Deletions within chromosome 22q11 in familial congenital heart disease. Lancet 1992;340:573-5.

3 Goldmuntz E, Driscoll D, Budarf ML, et al. Microdeletions of chromosomal region 22q11 in patients with congenital of chromosomal region 22q11 in patients with congenital

4 Nora J, Nora AH. Update on counselling the family with a fora J, Nora AH. Update on counselling the family with a first degree relative with a

5 Goodyear JE. Persistent truncus arteriosus in two siblings. Br Heart $\mathcal{F}$ 1961;23:194-6.

6 Brunson SC, Nudel DB, Gootman N, Aftalion B. Truncus arteriosus in a family. Am Heart $\mathcal{F}$ 1978;96:419-20.

7 Pierpont MEM, Gobel JW, Moller JH, Edwards JE. Cardiac malformations in relatives of children with truncus arteriosus or interruption of the aortic arch. $A m \mathcal{F}$ Cardio 1988;61:423-7.

8 Le Marec B, Odent S, Almange C, et al. Le truncus arteriosus: une maladie autosomique récessive? $\mathcal{f}$ Genet Hum 1989;37:225-30. 
9 Rein AJJT, Dollberg S, Gale R. Genetics of conotruncal malformations: review of the literature and report of a consanguineous kindred with various conotruncal malformations. Am $\mathcal{F}$ Med Genet 1990;36:353-5.

10 Wulfsberg EA, Zintz EJ, Moore JW. The inheritance of conotruncal malformations: a review and report of two siblings with tetralogy of Fallot with pulmonary atresia. Clin Genet 1991;40:12-16.

11 Pacileo G, Musewe NN, Calabró R. Tetralogy of Fallot in three siblings: a familial study and review of the literature. three siblings: a familial study an

12 Rein AJT, Sheffer R. Genetics of conotruncal malformations: further evidence of autosomal recessive inheritance. Am f Med Genet 1994;50:302-3.

13 Gardner RJM, Morrison PS, Abbott GD. A syndrome of congenital thrombocytopenia with multiple malformation and neurological dysfunction. $\mathcal{F}$ Pediatr 1983;102:600-2.

14 Thomas IT, Jewett T, Raines KA, Gash C, Garber P. New lethal syndrome of fetal akinesia with characteristic facia appearance, severe microphthalmia, microtia, and truncus arteriosus in two male sibs. Am 7 Med Genet 1993;46:1801.

15 Figuera LE, Ramirez-Duenas ML, Rangel-Villalobos $\mathrm{H}$, Cantù JM. Microphthalmia, mental retardation and failure to thrive: a new syndrome with probable autosomal recessive inheritance. Am ₹ Hum Genet Suppl 1996;59:A93.

16 Pizzuti A, Novelli G, Mari A, et al. Human homologue sequences to the Drosophila dishevelled segment polarity gene are deleted in the DiGeorge syndrome. Am $\mathfrak{F}$ Hum gene are deleted in the
Genet 1996;58:722-9.
17 Warburg M. Classification of microphthalmos and coloboma. $₹$ Med Genet 1993;30:664-9.

18 Van Mierop LHS, Kutsche LM. Cardiovascular anomalies in DiGeorge syndrome and importance of neural crest as a possible pathogenetic factor. Am f Cardiol 1986;58:133-7.

19 Driscoll DA Salvin J Sellinger B, et al. Prevalence of 22q11 microdeletions in DiGeorge and velocardiofacial microdeletions in syndromes: implications for genetic counselin

20 Webber SA, Hatchwell E, Barber JCK, et al. Importance of Webber SA, Hatchwell E, Barber JCK, et al. Importance of microdeletions of chromosomal region $22 \mathrm{q} 11$ as a cause of selected malformations of the ventricular outflow tract and aortic arch: a three-year prospective study. $\mathcal{F}$ Pediat 1996;129:26-32.

21 Digilio MC, Marino B, Giannotti A, Dallapiccola B. Chromosome 22q11 microdeletion and isolated conotruncal heart defects. Arch Dis Child 1997;76:79-81.

22 Debrus S, Berger G, de Meeus A, et al. Familial non-syndromic conotruncal defects are not associated with a 22q11 microdeletion. Hum Genet 1996;97:138-44

23 Digilio MC, Marino B, Giannotti A, Toscano A, Dallapiccola B. Recurrence risk figures of isolated tetralogy of Fallot after screening for 22q11 microdeletion. 7 Med Genet 1997;34:188-90.

24 Van Praagh $R$, Van Praagh S. The anatomy of common aortico-pulmonary trunk (truncus arteriosus communis) and its embryologic implications: a study of 57 necropsied and its embryologic implications: a s

25 Clark EB, Takao A. Developmental cardiology: morphogenesis and function. Mt Kisco, NY: Futura Publishing, 1990. 